\title{
Capital Markets Constrain Industry Scale
}

\author{
Eslyn L. Jean-Baptiste and Michael H. Riordan* \\ Columbia University
}

First draft: March 2003

This version: September 2003

\begin{abstract}
$\underline{\text { Abstract }}$
The paper considers an industry featuring agency problems between outside investors and entrepreneurs who manage the firms comprising the industry. In a range of circumstances, industry scale is independent of product market structure, and is determined solely by the amount of equity financing contributed by the entrepreneurs, and by the capital market's response to possible managerial malfeasance. Thus, in the face of capital market constraints, a change in productmarket concentration has no effect on market performance unless it occasions a change in the amount of inside equity financing.
\end{abstract}

\footnotetext{
* We thank Judy Chevalier, Matt Rhodes-Kropf, seminar participants at Columbia Business School and the University of California at Berkeley, and participants at the 2003 NBER Corporate Finance Summer Institute for helpful comments on earlier versions.
} 


\section{Introduction}

In their seminal article on the theory of the firm, Jensen and Meckling (1976) recognized that the managers who control a firm can chose between consuming perquisites ("non-pecuniary benefits") and maximizing the value of the firm, and that the agency costs of outside financing are determined jointly with the scale of the firm. We build on these important observations to show how credit market constraints limit the scale of an industry.

Jensen and Meckling's (1976) analysis was at the level of the firm, not the industry. They showed how the agency costs of outside equity reduced the optimal scale of a firm. In contrast, we consider the interaction of capital and product market competition, focusing on how default risk associated with managerial spending on perquisites causes the credit market to ration firms participating in the same product market. To be sure, Jensen and Meckling (1976, pp. 333-343) did recognize certain costs of debt, but this was mainly to explain why outside financing does not consist entirely of debt. In contrast, the main idea underlying our analysis is that managerial spending on perquisites is potentially a source of default risk.

Our model of capital market and product market competition between entrepreneurial firms yields an invariance result. Production by these firms is financed by inside equity and debt. In a range of circumstances, industry scale is independent of the number of competitors, and is determined solely by the capital market's response to possible managerial malfeasance and the amount of inside equity contributed by the

\footnotetext{
${ }^{1}$ Williams (1995) is similar in spirit. In Williams' model, the capital market constraints that control managerial spending on perquistites distort an industry's choice of technology. In equilibrium, more firms adopt a high marginal cost technology, resulting in a smaller industry scale.
} 
entrepreneurs who manage the firms. An additional competitor expands the market only to the extent the entrepreneur who manages the new firm brings additional equity to the industry. Thus, the degree of competition has a neutral effect on market performance, unless the total amount of inside equity changes with the number of competitors in the product market.

The idea that product market competition varies with the financial conditions of firms has been demonstrated for a number of industries, including supermarkets (Chevalier 1995a, 1995b; Chevalier and Scharfstein 1995, 1996) and airlines (Busse 2002). A leading theoretical explanation is the "limited liability effect" of capital structure commitments on the equilibrium price and quantity strategies of firms (Brander and Lewis 1986; Maksimovic 1988; Showalter 1995, 1996). An alternative possible explanation is that the capital market controls managerial misappropriation by rationing funds needed to finance production (Jensen and Meckling 1976; Bolton and Scharfstein 1990; and Albuquerque and Hopenhayn 2002). Our contribution is to develop the latter argument at the level of the industry rather than just at the level of the individual firm. We show that the equilibrium scale of an entrepreneurial industry depends on the extent of its reliance on outside funds to finance production, and that the market share of an individual firm depends both on its own financial condition and that of its rivals. Thus an industry's equilibrium competition in the product market is intertwined with its competition in capital markets. We remark further on the relationship between our theory and the received empirical and theoretical literatures as we go along.

Our approach departs from the conventional corporate finance wisdom that product market competition disciplines firms and their managers. The informal 
justification for this view is that competition fosters a form of natural selection that weeds out incompetent, dishonest and imprudent managerial teams. Hart (1983) argues more formally that competition reduces agency problems between managers and owners by revealing more information, but this result is sensitive to assumptions about the manager's utility function (Scharfstein (1988)). Hermalin (1992) and Schmidt (1997) also argue that the effect of competition on managerial incentives is ambiguous. Raith (2002) develops a model in which shareholders provide managers with stronger incentives to reduce costs when competition increases. Allen and Gale (2000) abstract from agency problems, and argue that competition is more effective than standard corporate government mechanisms at selecting more productive managerial teams. Our invariance result is in stark contrast to these ideas, although admittedly we restrict our attention to entrepreneurial firms. . $_{\text {The invariance result of course also departs from the conventional }}$ industrial organization wisdom.

The rest of our paper is organized as follows. The next section lays out our basic assumptions about the structure of the product market and the capital market, and establishes the optimality of simple debt contracts. Section 3 considers a monopoly market structure, and shows how agency considerations cause the credit market to constrain the scale of the firm below the neoclassical monopoly level. This section also further discusses the relationship between our analysis and that of Jensen and Meckling (1986). Section 4 generalizes the monopoly result to symmetric oligopoly, demonstrating

\footnotetext{
${ }^{2}$ Jensen and Meckling (1976, p. 329) similarly distance their analysis from the then prevailing versions of this conventional wisdom: "It is frequently argued that the existence of competition in product (and factor) markets will constrain the behavior of managers to ideal value maximization, i.e., that monopoly in product (or monopsony in factor) markets will permit larger divergences from value maximization. Our analysis does not support this hypothesis. The owners of a firm with monopoly power have the same incentives to limit divergences of the manager from value maximization. (i.e. the ability to increase their wealth) as do the owners of competitive firms."
} 
how the capital market constrains the scale of the industry. This section derives our basic invariance result: when capital market constraints are binding, equilibrium depends on the total amount of industry inside equity, and not on the number of symmetric competitors per se. The section also contrasts our analysis with Brander and Lewis (1986). Section 5 extends the analysis to the case of asymmetric inside equity, and shows that equilibrium industry scale depends on the total inside equity of credit-constrained firms and the number of unconstrained firms. This section also relates our results to some of the empirical literature on capital structure and product market competition. Section 6 draws some policy conclusions. All proofs are presented in the Appendix.

\section{Basic Economic Environment}

Consider an economy in which only $n$ entrepreneurs can sell a unique product, either because they each have a well-defined property right over the relevant production technologies, or because only they have the required managerial talent to run the production processes. ${ }^{\text {⿴囗 The }}$ market has the following structure. The production technologies exhibit constant returns to scale, and the average cost of production is equal to $c$. Inputs must be purchased in advance of production, and the opportunity cost of a unit of financial capital is $(1+r)$. Revenue is a function of the quantity of output, $R(Q)=P(Q) Q$, where $P(Q)$ is the (inverse) demand curve. The demand curve is downward sloping and continuous, as is the corresponding marginal revenue curve. Moreover, $R(0)=0$ and $R^{\prime}(0)>(1+r) c$.

\footnotetext{
${ }^{3}$ For example, FCC licensing of spectrum rights limits the number of competitors in markets for wireless telephony.
} 
We are interested in exploring how the credit market might constrain the product market outcome. Toward this end we assume that the entrepreneur is endowed with a limited amount of financial capital, $e_{i}$ and denote the total amount of "inside" capital in the industry as $E=\sum_{i=1}^{n} e_{i}$. The entrepreneurs invest these amounts in their respective enterprises, but must raise additional funds on the capital market in order to expand industry production beyond $\frac{E}{c}$. In order to produce quantity $q_{i}>\frac{e_{i}}{c}$, an entrepreneur must raise a sufficient amount of financial capital, $k_{i} \geq c q_{i}-e_{i}$, from outside investors. The capital market is perfectly competitive, and outside investors are willing to lend funds at an interest rate of $r$ when there is no default risk. Loans are repaid at the end of the period.

The agency problem for outside investors is that each entrepreneur has the ability to divert funds to non-productive managerial perquisites. More precisely, the entrepreneur can spend each dollar of financial capital either on production or on perquisites with a monetary-equivalent value of $\lambda$ (measured at the end of the period). $\lambda$ is commonly known to all agents. In addition, we assume that $0<\lambda<1+r$, which means that it would be inefficient for outside investors to fund managerial perquisites. The problem facing investors is that managerial spending on perquisites is not verifiable, and cannot be recovered if the entrepreneur/manager defaults on the loan and enters bankruptcy. ${ }^{-1}$ Therefore, investors are concerned about expropriation by managerial malfeasance.

\footnotetext{
${ }^{4}$ Default and bankruptcy are synonymous in our model. The important idea is that bankruptcy effectively shields entrepreneurs from the claims of lenders. In our simple model, there are no assets to liquidate in bankruptcy, so default means simply that creditors are not repaid.
} 
The market unfolds in two stages. At stage 1, the capital market supplies financial capital ( $K=\sum_{i=1}^{n} k_{i}$ ) that augments the entrepreneurs' initial investment of equity $(E)$. At stage 2, the entrepreneurs allocate available financial capital between productive inputs and managerial perquisites; any remaining funds are kept as reserves and invested at the prevailing rate $r$. Capital markets have rational expectations and at stage 1, supply funds up to the point of zero expected profits given rational expectations about the entrepreneurs' (monetary-equivalent) utility-maximizing decisions at stage 2 . These two conditions, utility-maximizing production and the capital-market competition, define industry equilibrium.

We emphasize our twin assumptions that, while production decisions and the related expenditures are not contractible, their outcomes are; that is revenues from production (and cash reserves) are verifiable and contractible. These assumptions capture the stylized facts that production decisions are a managerial prerogative precisely because these decisions are complex and require expertise. Managers can take advantage of the opacity of the firm's operations to outsiders and of the discretion that they enjoy over the use of the firm's resources to divert these resources instead of using them for productive purposes. ${ }^{\mathrm{B}}$ Thus managerial "stealing" is the process of transforming financial capital into private benefits or assets that cannot be verified or recovered by investors and courts. Because managers have limited liability and cannot be punished beyond the verifiable amount of the firm's income, this creates a moral hazard problem. When managers actually engage in production and do not steal, however, the resulting income can be

\footnotetext{
${ }^{5}$ In practice some operating expenditures are verifiable and most firms invest in plants and other assets that are sometimes used as collateral. However, as long as the operations of the firm require substantial investments in other assets that can be transferred (e.g. working capital) or are intangible (e.g. R\&D), the qualitative results of the model will hold.
} 
verified and recovered by debt-holders (as in Townsend (1979)). This is consistent with the fact that legal claims against sales receipts are usually enforceable in bankruptcy.

There is no role for outside equity in our model. The substitution of outside equity for debt would only increase an entrepreneur's incentive to divert capital spending to perquisites. Thus, the "capital market" is synonymous with the "credit market", and we restrict our attention to debt contracts as means of outside finance. A proof that this restriction does not entail any loss of generality is presented in the Appendix.

\section{Lemma. Simple debt contracts are optimal.}

\section{Monopoly}

The monopoly case $(n=1)$ provides initial insights into how the capital market constrains production decisions. Neoclassical monopoly profit is given by

$$
W(Q)=P(Q) Q-(1+r) c Q
$$

Our assumptions imply that the neoclassical monopoly output, $Q^{M}$, is positive and satisfies the first-order condition for profit-maximization, $R^{\prime}\left(Q^{M}\right)=(1+r) c$. We want to explore how the credit market might reduce equilibrium output below the monopoly level. Toward this end we assume that the entrepreneur is endowed with a limited amount of financial capital, $E<c Q^{M}$.

Figure 1 illustrates the industry equilibrium for the case in which the capital market constrains output below the neoclassical monopoly level. The concave curve is

\footnotetext{
${ }^{6}$ Jensen and Meckling (1976, pp. 330-343) recognize this point, and get around it by introducing additional agency costs of debt. We ignored these additional considerations in order to simplify and focus on our main idea that capital markets deal with agency costs by constraining industry size.
} 
the neoclssical monopoly profit and the upward sloping line is the maximum net benefit from diverting financial capital from production to perquisites. The equilibrium output is $\hat{Q}$, which is less than the neoclassical monopoly output $Q^{M}$. The crucial feature of this construction is that the two curves intersect at $\hat{Q}$, indicating that, in the equilibrium, the entrepreneur is just indifferent between production and perquisites. If the capital market were to lend additional funds, then, as we show below, the entrepreneur would have an incentive to spend everything on perquisites and default on the debt.

Figure 1 also makes clear that our results do not depend crucially on the linearity of the stealing technology. As long as the curve representing the benefits of stealing is not too concave and cuts the neoclassical profit curve from below, our conclusions are unaffected.

We now analyze the industry equilibrium more carefully. We begin by analyzing the entrepreneur's production decision given financial resources $(K+E)$, where $K$ is debt and $E$ is inside equity. The entrepreneur can invest some of its financial capital $c Q$ in production to generate end of period revenues $R(Q)$, save an amount $I$ as reserve and earn $I(1+r)$ and squander the rest of the funds on perquisites and obtain a private benefit equal to $\lambda(E+K-c Q-I)$. Any claims are paid out of revenues and reserves since spending on perquisites cannot be recovered in bankruptcy. Therefore, the entrepreneur's choice problem is:

$$
\begin{gathered}
\operatorname{Max}_{Q, I} \pi(Q, E, K)=[P(Q) Q+(1+r) I-(1+r) K]^{+}+\lambda(E+K-c Q-I) \\
\text { subject to } \quad I+c Q \leq E+K \quad I \geq 0 \quad Q \geq 0
\end{gathered}
$$


In the statement of this problem, the notation $[X]^{+} \triangleq \max \{X, 0\}$ recognizes the limited liability of the entrepreneur.

Two observations shed light on how the solution of this problem departs from the standard marginal analysis. First, it is never optimal for the entrepreneur to choose positive levels of production and reserves that are insufficient to pay the debt fully. The reason for this is that the entrepreneur is always better off "stealing" these funds (i.e. diverting these funds to perquisites). Second, it is never optimal for the entrepreneur to steal some funds while producing and saving enough to repay the debt in full. The intuition for this is that the entrepreneur is in effect stealing from himself when debt is repaid in full. Since stealing is inefficient, this behavior is suboptimal. These two facts imply that stealing is an all or nothing proposition for the entrepreneur, and that, in equilibrium, stealing cannot coexist with strictly positive output.

Thus the entrepreneur makes a binary decision between investing in perquisites and investing in production. The entrepreneur elects to spend financial capital on production if and only if $I+c Q=E+K$ and $\pi(Q, E, K) \geq \lambda(E+K)$ for some $0<Q \leq \frac{E+K}{c}$. These expressions combine to imply the following incentivecompatibility constraint

\footnotetext{
${ }^{7}$ Another way to understand the entrepreneur's decision is to recognize the option-like structure of her levered equity. The entrepreneur must choose between "legitimate" compensation through productive behavior and "illegitimate" gains through stealing. However, the legitimate rewards are obtained only if the debt is repaid in full. Once debt is repaid, all the surplus goes to the entrepreneur. Therefore conditional on repaying the debt, the entrepreneur will always behave efficiently and avoid stealing; her option is "in the money". However, when debt is expected not to be repaid in full (the option is out of the money), the entrepreneur cannot get any legitimate rewards and so her best strategy is to get the maximum illegitimate rewards and steal everything.

${ }^{8}$ This is due to the assumption that stealing is inefficient. Relaxing this assumption would not change the flavor of our results. More on this below.
} 


$$
W(Q) \geq \lambda(E+K)-(1+r) E \text { for } 0<Q \leq \frac{E+K}{c}
$$

The left-hand side of the inequality is the total production surplus available to the entrepreneur. The right-hand side is the premium the entrepreneur obtains from the monetary-equivalent value of perquisites. Thus, this is a "no-stealing constraint"; the entrepreneur has no incentive to divert working capital to perquisites.

The monopolist never produces more than $Q^{M}$ because beyond the neoclassical monopoly output the marginal revenue of an additional dollar invested in production is lower than $(1+r)$ and this is always dominated by saving when output is positive (and debt is fully repaid). Also, if $E+K<c Q^{M}$, and the entrepreneur produces at all, then she invests all her capital in production; that is, the entrepreneur never chooses a quantity $0<Q<\max \left(\frac{E+K}{c}, Q^{M}\right)$. The reason for this is that, because quantity is positive, there is no stealing, and any amount not used in production is saved as reserve; however, the reserve only generates $(1+r)$ when production an extra dollar invested in production generates $\frac{R^{\prime}(Q)}{c}>(1+r)$. In other words, the firm produces $\bar{Q}(E, K)=\min \left\{\frac{E+K}{c}, Q^{M}\right\}$, if this value satisfies the above incentive-compatibility constraint, and produces $Q=0$ otherwise.

The capital market anticipates the behavior of the entrepreneur and will provide funds up to $\hat{K}$ satisfying

$$
P\left(\frac{E+\hat{K}}{c}\right) \frac{E+\hat{K}}{c}-(1+r+\lambda)(E+\hat{K})=-(1+r) E
$$


Any outside investment beyond $\hat{K}$ would lead to bankruptcy, depriving outside investors of any repayment of principal and interest.

We are now in a position to characterize the industry equilibrium. Define $\hat{Q}$ as the strictly positive root of

$$
[P(\hat{Q})-(1+r+\lambda) c] \hat{Q}=-(1+r) E
$$

The quantity $\hat{Q}=\frac{\hat{K}+E}{c}$ is the maximum industry scale that the capital market is willing to finance. If $\hat{Q} \geq Q^{M}$, then the capital market stands ready to fund all that is required by a monopolist, and exerts no constraint on industry scale. Otherwise, the capital market constrains the firm from producing the neoclassical monopoly output. Given that investors can save on their own at rate $r$, we can without loss of generality restrict attention to equilibria in which entrepreneurs raise exactly the amount that the market expects them to spend on production.

Proposition 1. A monopolist produces $Q=\min \left\{\hat{Q}, Q^{M}\right\}$, financed by inside equity $E$ and loans $K=c Q-E$. The constrained output $\hat{Q}$ is increasing in E and decreasing in $\lambda$.

It is noteworthy that more effective corporate governance, represented by a reduction in $\lambda$, might increase the output and lower the price of the product. A lower value of $\lambda$ increases the debt ceiling that the capital market imposes on the firm. Therefore, if agency considerations constrain the size of the firm, then it follows that better corporate governance expands output. In this case, an improvement in corporate 
governance, that lessens a manager's ability to benefit from wasteful non-pecuniary consumption, improves social welfare.

It is also noteworthy that an increase in the amount of equity capital supplied by entrepreneur might expand output. The fact that $\hat{Q}$ is increasing in $E$ means that the capital market is willing to fund a larger scale of production if the entrepreneur/manager has a greater amount of equity capital at stake.

The fact that there is never any stealing in equilibrium is a direct consequence of the assumption that stealing is inefficient, i.e. $\lambda<1+r$. Relaxing this assumption would not change the flavor of the proposition but would generate equilibrium stealing as is illustrated in the Appendix. However, this assumption is useful because it allows us to focus on the product-market effects of credit-market constraints, rather than on the amount of equilibrium stealing. The latter element is, in our view, the more obvious but less important manifestation of agency costs.

We illustrate the proposition with the simple example of a linear inverse demand function of the form $P(Q)=A-Q$. It is straightforward to verify that the monopoly output is given by $Q^{M}=\frac{A-(1+r) c}{2}$. The parametric restriction $A \geq(1+r) c$ is necessary for production to occur ever. The minimum level of inside equity $E^{M}$ that can support the monopoly output is given by replacing $\hat{Q}$ by the value for $Q^{M}$ in (1.1)

$$
E^{M}=\left[-\frac{[A-(1+r+2 \lambda) c][A-(1+r) c]}{4(1+r)}\right]^{+} .
$$

\footnotetext{
${ }^{9}$ Whether or not the amount of industry debt $(\hat{Q}-E)$ increases with $E$ is ambiguous.
} 
If parameters are such that $A \geq(1+r+2 \lambda) c$, then $E^{M}=0$, and the monopoly output obtains even when the entrepreneur is penniless. The resulting equilibrium can be written as: $Q^{*}=\left\{\begin{array}{ccc}Q^{M}=\frac{A-(1+r) c}{2} & \text { if } & E \geq E^{M} \\ \hat{Q}=\frac{1}{2}\left(A-(1+r+\lambda) c+\sqrt{[A-(1+r+\lambda) c]^{2}+4(1+r) E}\right) & \text { if } & E<E^{M}\end{array}\right.$.

Note also that when capital market imperfections constrain output below the monopoly level, that is, when $E<E^{M}$ (or equivalently when $\hat{Q}<Q^{M}$ ), the equilibrium output increases with the amount of inside equity.

Inside equity capital is also important for understanding industry growth in a dynamic monopoly model. In the Appendix we add an additional production period to the monopoly model, and show that this relaxes the capital market incentive compatibility constraint. The option to produce and earn a monopoly rent in the second period effectively reduces the entrepreneur's incentive to steal in the first period, assuming that the entrepreneur losses her property right in the event of bankruptcy. Moreover, retained profits from the first period contribute inside equity capital in the second period. The spirit of our two-period analysis is similar to Albuquerque and Hopenhayn (2002) who consider a richer dynamic model of a credit-constrained entrepreneurial firm. 10

A discussion of the relationship between this analysis and the one in Jensen and Meckling (1976) also is presented in the Appendix. The main differences are that our

\footnotetext{
${ }^{10}$ The Albuquerque and Hopenhayn (2002) model features an infinite horizon, demand uncertainty, and a more general "stealing" technology. The optimal debt contract does not have a simple structure; indeed, once the firm grows to optimal size, the entrepreneur is paid a fixed dividend and the "lender" becomes a residual claimant. Before this point, however, the entrepreneur receives nothing, i.e. all accumulated "inside equity" is reinvested in the firm, as in our model.
} 
model (i) assumes that perquisites are inefficient, and (ii) allows for the possibility of default (and bankruptcy) caused by managerial spending on perquisites. We have shown that, if the capital market were to provide enough financial capital to achieve a monopoly scale, then the entrepreneur who manages the firm might choose to spend these resources on perquisites, produce nothing, and declare bankruptcy. This case occurs when monopoly rents are small relative to the value of perquisites. In this case, the capital market responds by reducing the amount of financial capital available to the firm, thus reducing scale below the monopoly level.

\section{Symmetric Oligopoly}

We now consider competition between $n \geq 2$ symmetric firms who compete in the product market and also compete for funds in the capital market. Barriers to entry into the product market are absolute.

The product market has the same structure as before except for the number of market participants. The market demand curve and marginal revenue curve are downward sloping and continuous, and all firms possess the same constant returns production technology. Inputs are purchased in advance of production, and the capital market is competitive.

The symmetric Cournot equilibrium is a benchmark. This Cournot solution has an industry output $Q^{n}=n q^{n}$ satisfying

$$
P\left(Q^{n}\right)+q^{n} P^{\prime}\left(Q^{n}\right)=1+r .
$$


$Q^{n}$ is non-decreasing in $n$. A sufficient condition for a unique and symetric Cournot equilibrium is that $P(Q)$ is log-concave (Amir and Lambson, 2000). Let $q^{C}\left(Q_{-i}\right)$ represent the Cournot best response function for a representative firm (Firm $i$ ) when competitors produce $Q_{-i}$.

We consider how agency problems can result in an industry scale below the Cournot level. Toward this end, we assume that each firm is owned and managed by an entrepreneur with limited equity capital, and uses debt financing to expand production. The agency problem is that each entrepreneur can spend these funds on non-productive managerial perquisites, receiving a proportional private benefit. Therefore, as in the monopoly case, the capital market advances funds to firms in this industry only if an appropriate incentive compatibility constraint holds. The constraint assures outside investors that the entrepreneurs have incentives to allocate financial capital to production rather than to perquisites. We show that the capital-market incentive-compatibility constraint on symmetric entrepreneurial firms competing in a Cournot product market can constrain industry scale. Cournot interaction in the product markets is a very natural framework for our analysis of equilibrium industry capacity. Indeed, the main point of the paper is that because firms must acquire capacity first before engaging in production, they need to convince capital markets to finance these investments in capacity. The need for capacity commitment, is a feature that is also emphasized in the setting of Kreps and Scheinkman (1983) who show that Bertrand competition yields Cournot outcomes .

A symmetric oligopoly equilibrium for a financially constrained industry is illustrated Figure 2. The downward-sloping line labeled $q^{C}\left(Q_{-i}\right)$ is the standard Cournot 
reaction curve of a representative firm. The line labeled $\hat{q}\left(Q_{-i}\right)$ is the reaction firm of the firm with limited equity under financial constraint, and is defined implicitly by

$$
\left[P\left(Q_{-i}+\hat{q}\right)-(1+r+\lambda) c\right] \hat{q}=-(1+r) e .
$$

The reaction curve of the firm is the minimum of the Cournot and financial constrained reaction curves (the darker continuous line in the graph). This curve is derived by an extension of Proposition 1. If both the firm and its investors expect rival firms to produce a cumulative output $Q_{-i}$, then the profit-maximizing response of the investors is to supply sufficient financial capital to produce $\min \left\{q^{C}\left(Q_{-1}\right), \hat{q}\left(Q_{-1}\right)\right\}$. The diagram illustrates that the capital market rations a representative firm if the expected cumulative output of rivals is sufficiently great. The symmetric equilibrium occurs where the reaction curve cuts upward sloping line labeled $\frac{Q_{-i}}{n-1}$; in the case of duopoly, for example, this would be a $45^{\circ}$ line.

We now proceed to a more detailed analysis. Oligopoly competition occurs in two stages. At Stage two, the entrepreneurs play a simultaneous move game in which each allocates its financial capital to production or perquisites. These production decisions form a Nash equilibrium. At Stage one, the capital market supplies funds to each firm to earn a normal competitive return given rational expectations about the Nash equilibrium of the ensuing production game. The conditions of (1) Nash equilibrium of the production game, and (2) zero-profits of outside investors, define an industry equilibrium. In this section, we focus on a fully symmetric equilibrium.

We adopt the following notation. Let $e<c q^{n}$ denote the financial endowment of a representative entrepreneur, and $E=n e$ the total amount of inside equity in the 
industry. Similarly, let $K=n k$ denote amount of industry debt that is raised on the capital market. If financial capital is fully invested in production, then industry output is $Q=n q=\frac{n(e+k)}{c}$.

Analysis of the production game is crucial for understanding capital market equilibrium. Consider the reaction function of Firm $i$. Suppose that the firm has borrowed $k_{i}$, and expects its rival to produce a quantity of output $Q_{-i}$. The choice problem confronting the entrepreneur/manager of Firm $i$ is:

$$
\begin{gathered}
\underset{q_{i} I_{i}}{\operatorname{Max}_{i}} \pi_{i}\left(q_{i}, e, k_{i}\right)=\left[P\left(Q_{-i}+q_{i}\right) q_{i}+(1+r) I_{i}-(1+r) k_{i}\right]^{+}+\lambda\left(e+k_{i}-c q_{i}-I_{i}\right) \\
\text { subject to } \quad I_{i}+c q_{i} \leq e+k_{i} \quad I_{i} \geq 0 \quad q_{i} \geq 0
\end{gathered}
$$

where $I_{i}$ is the amount of financial capital the firm holds in cash reserves.

The similarities with the monopolist's production problem are obvious, and similar arguments to the monopoly analysis yield two conclusions. First, the rational entrepreneur elects to produce a positive quantity $0<q_{i} \leq \frac{e+k_{i}}{c}$ if and only if this quantity satisfies the incentive-compatibility constraint

$$
w\left(q_{i} ; Q_{-i}\right)=P\left(Q_{-i}+q_{i}\right) q_{i}-(1+r) c q_{i} \geq \lambda\left(e+k_{i}\right)-(1+r) e,
$$

where the left-hand side is the surplus from production available to the entrepreneur and the right-hand side is the perquisite premium. Second, the entrepreneur never produces more than her Cournot best reply, i.e. $q_{i} \leq q^{c}\left(Q_{-i}\right)$, and may produce strictly less is financial capital is insufficient. Thus, in reaction to $Q_{-i}$, the firm produces the quantity $\bar{q}_{i}\left(Q_{-i} ; e, k_{i}\right)=\min \left\{\frac{e+k_{i}}{c}, q^{c}\left(Q_{-i}\right)\right\}$ if this quantity satisfies the above incentive- 
compatibility constraint, and produces $q_{i}=0$ otherwise. Because the Cournot reaction curve $q_{i}^{n}\left(Q_{-i}\right)$ is non-increasing, Firm $i$ 's reaction curve at Stage 2 is a discontinuous function of the form

$$
q_{i}\left(Q_{-i} ; e, k_{i}\right)=\left\{\begin{array}{ccc}
\bar{q}_{i}\left(Q_{-i} ; e, k_{i}\right) & \text { if } & Q_{-i} \leq \bar{Q}_{-i}\left(e, k_{i}\right) \\
0 & \text { if } & Q_{-i}>\bar{Q}_{-i}\left(e, k_{i}\right)
\end{array}\right.
$$

where $\bar{Q}_{-i}\left(e, k_{i}\right)$ is defined by the binding incentive-compatibility constraint

$$
w\left(\bar{q}_{i}\left(\bar{Q}_{-i}\right) ; \bar{Q}_{-i}\right)=\lambda\left(e+k_{i}\right)-(1+r) e .
$$

Thus, limited financial capital and the opportunity to consume perquisites modify the firm's best-response curve. It follows from these conclusions that, for an arbitrary subgame (defined by $k_{i}, i=1, \ldots n$ ), the equilibrium production profile $\left(q_{i}^{*}\right)$, satisfies either $q_{i}^{*}\left(e, k_{i}\right)=\bar{q}_{i}\left(Q_{-i}^{*} ; e, k_{i}\right)$, in which case Firm $i$ 's incentive-compatibility constraint holds, or $q_{i}^{*}\left(e, k_{i}\right)=0$ and the constraint fails.

Given the capital market's rational expectations, investors never finance a firm when they expect the entrepreneur to steal resources. Satisfaction of the capital market incentive compatibility constraint implies that there is no diversion of funds to perquisites, and, because investors can save on their own, we safely can restrict attention to equilibria in which capital markets provide funds only when they expect all the firm's capital to be used on production, that is when $q_{i}=\frac{e+k_{i}}{c}$. If $q_{i}<\frac{e+k_{i}}{c}$, then marginal investors could just as well withdraw their investment in the firm.

\footnotetext{
${ }^{11}$ The equilibrium of that subgame is not necessarily unique since there could exist several equilibria of the subgame in which one or more players produce nothing and steal all the funds.
} 
In a symmetric industry equilibrium, the capital market is willing to supply funds to a representative firm up to the point that the firm has no incentive to steal given the production decisions of its rivals. Therefore, the debt capacity of a representative firm is a symmetric equilibrium (with each firm producing $q$ ) is the value of $k$ satisfying the binding incentive-compatibility constraint

$$
\left[P\left((n-1) q+\frac{e+k}{c}\right)-(1+r+\lambda) c\right] \frac{e+k}{c}=-(1+r) e .
$$

Moreover, if the capital market declines to supply funds that are not used for production, then $q=\frac{e+k}{c}$. It follows that equilibrium production of a representative firm $\hat{q}^{n}$ in a symmetric industry of size $n$ is defined exactly by the expression

$$
\left[P\left(n \hat{q}^{n}\right)-(1+r+\lambda) c\right] \hat{q}^{n}=-(1+r) e .
$$

The production of a representative firm is financed by inside equity $e$, and debt $\hat{k}=c \hat{q}^{n}-e$.

The capital market does not constrain product market competition when $\hat{q}^{n} \geq q^{n}$. Conversely, industry output is below the Cournot level when the capital market constraint binds. Note that when the capital market constraint binds, total industry output satisfies $\left[P\left(\hat{Q}^{n}\right)-(1+r+\lambda) c\right] \hat{Q}^{n}=-(1+r) E$ where $\hat{Q}^{n}=n \hat{q}^{n}$. This shows that, when the total amount $E$ of inside equity available to the industry is constant, and when the capital market constraint binds, the total industry output does not change with the number of firms. 
Proposition 2. In a symmetric oligopoly, there is a unique symmetric equilibrium in which each firm produces $q=\min \left\{\hat{q}^{n}, q^{n}\right\}$, financed by inside equity e and loans $k=c q-e$. The constrained output $\hat{q}^{n}$ is increasing in e and decreasing in $\lambda$. Furthermore, if the capital market constraint binds for $n$ entrepreneurs (i.e. $\hat{q}^{n}<q^{n}$ ), then it also binds for $(n+1)$, holding the total amount of industry inside equity constant, and total industry output therefore does not change with an increase in the number of firms.

It is remarkable that the industry scale can be invariant to market concentration. While the standard Cournot industry output strictly increases in the number of active firms (Amir and Lambson, 2000), the financially-constrained industry output does not depend on $n$. That is, if $Q^{M}>\hat{Q}$, then $Q^{n}>Q^{M}$, and industry scale is invariant to market concentration in a symmetric equilibrium (keeping total inside equity $E$ constant and adjusting each individual firm's inside equity to the level $e=\frac{E}{n}$ ). When industry output is not constrained by the agency problem confronting entrepreneurs and outside investors, each firm produces the symmetric Cournot output, and an increase the number of firms expands the scale of the industry.

Note that capital market constraint necessarily binds as the industry becomes less concentrated holding industry inside equity constant. The perfectly competitive output level $Q^{*}$ satisfies

$$
P\left(Q^{*}\right)=(1+r) c
$$


While the Cournot output converges to $Q^{*}$ as $n \rightarrow \infty$, the equilibrium output of a financially-constrained industry remains at a scale $\hat{Q}<Q^{*}$.

Similarly to the monopoly model, an increase in the amount of inside equity supplied by entrepreneurs might expand industry scale. New entry expands the market only to the extent that the new entrant contributes additional inside equity to the industry. New entrants that rely more heavily on debt than inside equity exert less competitive pressure on the product market.

Also as in the monopoly model, an improvement in industry-wide corporate governance improves social welfare by expanding the market. We have argued that agency problems can cause credit markets to limit the scale of an industry. An interesting corollary of this general point is that private parties should not be expected to invest optimally in corporate governance. The benefits of market expansion accrue partly to consumer welfare that would not be internalized by entrepreneurs when organizing their firms. From this perspective, a public policy toward corporate governance could be as important as antitrust policy for increasing social welfare.

We now illustrate our analysis of symmetric oligopoly with the linear demand example from above. When the demand function is linear, the standard Cournot output is given by $q^{n}=\frac{A-(1+r) c}{n+1}$. This equilibrium can be supported only if each entrepreneur's inside equity satisfies the condition $e \geq e^{n}=\left[-\frac{[A-(1+r+(n+1) \lambda) c][A-(1+r) c]}{(1+r)(n+1)^{2}}\right]^{+}$.

This expression shows that when $n$ is small enough (that is $n \leq \frac{A-(1+r+\lambda) c}{\lambda c}$ ) the unique and symmetric Cournot equilibrium can be supported with zero inside equity. As 
in the monopoly case this is possible only if parameters are such that $A \geq(1+r+\lambda) c$.

Furthermore, when $n \geq \frac{2[A-(1+r) c]}{\lambda c}-1$ we have $\frac{d e^{n}}{d n} \leq 0$.

However, when inside equity is low enough (that is $e<e^{n}$ ), the unique equilibrium output is $\hat{q}^{n}=\frac{1}{2 n}\left(A-(1+r+\lambda) c+\sqrt{[A-(1+r+\lambda) c]^{2}+4 n(1+r) e}\right)$. Note that in this case $\frac{\partial \hat{q}^{n}}{\partial e}>0$ and $\frac{\partial \hat{q}^{n}}{\partial \lambda}>0$. Replacing $n e$ by $E$ in the expression for $\hat{q}^{n}$, it is clear that the expression $n \hat{q}^{n}$ is independent of $n$ when $E$ is constant.

In order to illustrate the effect of capital market constraints on the outcome of product market competition, consider the case of splitting a constrained monopolist into two identical firms. According to the above analysis, a monopolist is constrained if parameters are such that $E<E^{M}=\left[-\frac{[A-(1+r+2 \lambda) c][A-(1+r) c]}{4(1+r)}\right]^{+}$and $(1+r) c \leq A<(1+r+2 \lambda) c$. Suppose that the monopoly firm is split into two identical firms each with equity $e=\frac{E}{2}$. This split changes total equilibrium output from the constrained monopoly level $\hat{Q}^{M}=\frac{1}{2}\left(A-(1+r+\lambda) c+\sqrt{[A-(1+r+\lambda) c]^{2}+4(1+r) E}\right)$ to the constrained duopoly output $\hat{Q}^{D}=2 \hat{q}^{D}=\frac{1}{2}\left(A-(1+r+\lambda) c+\sqrt{[A-(1+r+\lambda) c]^{2}+4(1+r) E}\right)$, that is total output does not change at all.

We close this section by comparing our analysis of symmetric oligopoly with Brander and Lewis (1986). Brander and Lewis identified the "limited liability effect" of 
debt, namely, that increased debt encourages managers to expand production in order to increase profits in high-demand and low-cost states of the world in which the firm remains solvent. No such effect appears in our model. There are several differences between our model of symmetric oligopoly and the Brander-Lewis model explaining this. First, and most importantly, managers have the option of spending working capital on perquisites. Secondly, the firm is equity-constrained, i.e. entrepreneurs contribute a limited amount of financial capital, and there is no role for outside equity. Third, and least importantly, there is no product market uncertainty. Product market uncertainty is key ingredient of the Brander-Lewis limited liability effect, but it is not a sufficient ingredient. Nothing important would change if we were to introduce product market uncertainty into our model of a capital-constrained industry. The capital market would still ration firms in order to prevent the misappropriation of working capital, and the firm would be unable to expand production because of its financial constraints. The only difference is that firms' output level would be constrained below the Brander-Lewis equilibrium level rather than the Cournot level. Thus, if our model were extended to product market uncertainty, the limited liability effect would reappear under certain conditions even in a capital-constrained industry. If the capital-market constraint were slack, however, then the limited liability effect identified by Brander and Lewis (1988) would determine the equilibrium level of output.. In this way our model lays the groundwork for a more general framework with richer empirical predictions.

\section{Asymmetric equity}


We now allow that the otherwise symmetric entrepreneurs supply different amounts of equity capital. We show that industry scale still depends on the total amount of inside equity of constrained firms, and when all firms are constrained, a firm's share of the product market is equal to its share of industry inside equity.

Suppose Firm $i$ has equity capital $e_{i}<c q^{c}$, has borrowed $k_{i}$, and expects its rivals to produce a cumulative quantity $Q_{-i}$. A similar analysis to the symmetric case allows us to conclude that the firm's best response is a discontinuous function: the entrepreneur produces $q_{i}\left(Q_{-i} ; e_{i}, k_{i}\right)=\bar{q}_{i}\left(Q_{-i}, e_{i}, k_{i}\right)$ if and only if $Q_{-i} \leq \bar{Q}_{-i}$ (where $\bar{Q}_{-i}$ is defined by $W\left(\bar{q}_{i}\left(\bar{Q}_{-i}\right) ; \bar{Q}_{-i}\right)=\lambda\left(e_{i}+k_{i}\right)-(1+r) e_{i}$ as in the symmetric case) and nothing otherwise.

The capital market anticipates these incentives and advances funds to each firm up the point at which the incentive-compatibility constraint binds, that is $\left[P\left(Q_{-i}+\frac{e_{i}+k_{i}}{c}\right)-(1+r+\lambda) c\right] \frac{e_{i}+k_{i}}{c}=-(1+r) e_{i}$. Given the investors' rational expectations and their ability to invest on their own at rate $r$, we can restrict our attention to equilibria in which each firm is expected to invest all its funds in production, that is $q_{i}=\frac{e_{i}+k_{i}}{c}$. It is straightforward to verify that in equilibrium there can be only two types of firms. One subset of firms are constrained by agency problems and therefore are not producing the Cournot best response to their competitors' output; i.e. their output is characterized by $q_{i}\left(e_{i}, k_{i}\right)<q_{i}^{n}\left(Q_{-i}\right)$ and $\left[P\left(Q_{-i}+q_{i}\right)-(1+r+\lambda) c\right] q_{i}=-(1+r) e_{i}$. The other set of firms are unconstrained by the capital market and are on their Cournot best response curves; $\quad$ i.e. $\quad q_{i}\left(Q_{-i} ; e_{i}, k_{i}\right)=q_{i}^{n}\left(Q_{-i}\right) \quad$ and 
$\left[P\left(Q_{-i}+\frac{e_{i}+k_{i}}{c}\right)-(1+r+\lambda) c\right] \frac{e_{i}+k_{i}}{c} \geq-(1+r) e_{i}$. Equilibrium is described by the

following proposition.

Proposition 3. With an asymmetric allocation of inside equity, equilibrium is essentially unique $\frac{12}{12}$ and can be characterized as follows. Some firms are unconstrained and produce the Cournot best response to their competitors' output while others are constrained and produce less than their best response. Furthermore, all unconstrained firms produce the same quantity of output and have higher levels of equity and output than the constrained firms. The debt and output levels of the constrained firms are proportional to the amount of their contributions of inside equity. Finally, splitting a constrained firm into smaller firms does not change total industry output.

Naturally, the unconstrained firms are those with more equity. These firms are on their Cournot best response curves, and it is no matter whether they finance production with debt or equity as long as their capital market constraints remain slack (Modigliani and Miller (1958)). Among the subset of constrained firms, those with more equity are able to borrow more and have a larger market share. All constrained firms are equally leveraged (i.e. have the same debt-equity ratio), while unconstrained firms are less leveraged than their constrained competitors.

\footnotetext{
${ }^{12}$ Equilibrium outputs of all firms and the capital structure of constrained firms is unique. As discussed below, there is an inconsequential indeterminancy in the capital structure of unconstrained firm.
} 
Increasing the amount of equity financing of an unconstrained firm has no effect on equilibrium output. However, this is not true for constrained firms and an increase in the equity of these firms does increase output. Similarly, splitting a constrained firm into separate firms does not change the total level of output; the output of the original firm is just split between the spin-offs proportionally to the split of equity. In contrast, splitting an unconstrained firm or reallocating equity from constrained to unconstrained firms can affect equilibrium output.

It is interesting to consider the bilateral incentives to merger in our model. If a credit-constrained firm acquires a competitor, and finances the acquisition with debt, then industry output decreases and the product price rises to the extent that the merger reduces industry inside equity. This capital market response to a horizontal merger is not discussed in the Horizontal Merger Guidelines published by the U.S. Department of Justice. Such a consideration also is absent from Salant, Switzer, and Reynolds' (1983) classic analysis of bilateral merger incentives for the standard Cournot model. A bilateral merger might be profitable in our model, when it is not profitable in the standard model, if capital market constraints reduce the ability of rival firms to expand in response to an increase in product price.

We close this section by relating our results to some relevant empirical literature. Various empirical studies establish a link between product market behavior and financial conditions. For instance, Chevalier (1995a) documents that the leveraged recapitalizations of supermarkets have a positive effect on the stock returns of competing firms. Chevalier (1995a), Phillips (1995) and Kovenock and Phillips (1997) show that firms that increase leverage tend to reduce capacity while their rivals are likely to expand. 
These empirical regularities are sometimes interpreted as indicating a softening of competition that contradicts the limited liability effect of debt on output strategy. In contrast, out theory supports a negative relationship between leverage and output. In our model, the amount of inside equity constrains a firm's borrowing capacity, and more leveraged firms are less able to attract further outside finance in order to expand production. To the extent that leveraged buy-outs and similar recapitalizations exhaust a firm's debt capacity, our model predicts that these transactions would tend to decrease a firm's output. This creates an opportunity for firms with more financial slack to expand or for new firms to enter the industry.

\section{Conclusion}

Although it is widely recognized that agency problems between investors and controlling insiders are a major impediment to the financing of firms, the impact of these problems on the outcome of the product market is not well understood. This paper has argued that in some circumstances, capital market constraints may be more important for consumer welfare than product market structure. In particular, when moral hazard pervades the relationship between investors and firms, increased competition may not result in the expected expansion in output and reduction in prices, unless it is accompanied by an increase in industry inside equity.

A recognition that the firms in an industry compete in both product and capital markets has potentially important public policy implications. Our analysis suggests that antitrust regulation should include the financial conditions of firms in the analysis of the competitive impact of mergers and splits. Similarly, policies that heighten competitive 
pressure in an industry, such as trade liberalization, could exacerbate the insiders' incentive to loot the firm. As a consequence, the flexibility of local corporate governance arrangements can affect the successful implementation of these policies.

An interesting extension of the model is to allow firms to choose governancerelated variables. Indeed, in the medium and long run, corporate governance arrangements (as well as the legal structure) can and do change with the firm's environment. Tighter corporate governance schemes that decrease the insiders' discretionary power or increase outsiders' monitoring ability make stealing less attractive; however, because of their very intrusiveness, they may come at the cost of lower productivity of insiders. In other words more intrusive governance schemes may decrease the insiders' marginal benefit of stealing and at the same time adversely impact the firm's cost structure. Changes in the competitive environment are likely to affect the firm's perception of this trade-off. The analysis of these more complex interactions is left for further research. 


\section{APPENDIX}

\section{A1: Optimality of simple debt contracts}

Debt contracts can be used to achieve any out come that can be achieved with other feasible contracts. To see why, let $(\mathrm{S}(\mathrm{R}), \mathrm{K})$ represent a contract that specifies the investors return $\mathrm{S}(\mathrm{R})$ as a function of revenue $\mathrm{R}(\mathrm{Q})$, and the level of outside financing $\mathrm{K}$.

Define:

$$
\begin{gathered}
W(S, K)=\operatorname{Max}_{Q} \quad W(S, K, Q)=R(Q)-S(R)+\lambda(E+K-c Q) \\
\text { s.t. } S(R) \leq R \quad Q \leq \frac{E+K}{c}
\end{gathered}
$$

The first constraint represents the entrepreneur's limited liability and the fact that private benefits can never be recovered, and the second constraint is the budget constraint. Let $\mathrm{Q}^{*}$ be the solution to that problem. The contract $\mathrm{S}(\mathrm{R})$ is feasible if $S\left(R\left(Q^{*}\right)\right) \geq K(1+r)$, that is investors expect to break even. Therefore the optimal contract solves the following problem:

$$
\begin{array}{ll}
\underset{S, K}{\operatorname{Max}} & W(S, K) \\
& \text { s.t. } S\left(R\left(Q^{*}\right)\right) \geq K(1+r) .
\end{array}
$$

For any optimal contract $(\mathrm{S}(\mathrm{R}), \mathrm{K})$, the debt contract $(\min (K(1+r), R(Q)), K)$ yields the same outcome. To see why, if $\mathrm{Q}^{*}$ is the outcome under contract $(\mathrm{S}(\mathrm{R}), \mathrm{K})$ then we must have $R\left(Q^{*}\right)-S\left(R\left(Q^{*}\right)\right)-\lambda c Q^{*} \geq R(Q)-S(R(Q))-\lambda c Q$ for all $Q \leq \frac{E+K}{c}$. Since contract $(S(R), K)$ is feasible, we have

$$
R\left(Q^{*}\right)-\min \left(R\left(Q^{*}\right), K(1+r)\right)-\lambda c Q^{*} \geq R\left(Q^{*}\right)-S\left(R\left(Q^{*}\right)\right)-\lambda c Q^{*}
$$


Since $(S(R), K)$ is optimal, any contract $\left(S^{\prime}(R), K\right)$ such that $S^{\prime}(R)=S(R)$ for $R \neq R^{\prime}$ and $S^{\prime}\left(R^{\prime}\right)=\min \left\{S\left(R^{\prime}\right), K(1+r)\right\}$ for some $R^{\prime}$ that corresponds to output $Q^{\prime} \leq \frac{E+K}{c}$, is also optimal and yields output $Q^{*}$; otherwise $S(R)$ cannot be optimal. As a consequence:

$$
\begin{aligned}
R\left(Q^{*}\right)-\min \left(R\left(Q^{*}\right), K(1+r)\right)-\lambda c Q^{*} & \geq R\left(Q^{*}\right)-S\left(R\left(Q^{*}\right)\right)-\lambda c Q^{*} \\
& \geq R\left(Q^{\prime}\right)-\min \left(S\left(R\left(Q^{\prime}\right)\right), K(1+r)\right)-\lambda c Q^{\prime} .
\end{aligned}
$$

Since $S\left(R\left(Q^{\prime}\right)\right) \leq R\left(Q^{\prime}\right)$ we have

$$
\begin{gathered}
R\left(Q^{*}\right)-\min \left(R\left(Q^{*}\right), K(1+r)\right)-\lambda c Q^{*} \geq R\left(Q^{\prime}\right)-\min \left(S\left(R\left(Q^{\prime}\right)\right), K(1+r)\right)-\lambda c Q^{\prime} \\
\geq R\left(Q^{\prime}\right)-\min \left(R\left(Q^{\prime}\right), K(1+r)\right)-\lambda c Q^{\prime} .
\end{gathered}
$$

This simply says that $Q^{*}$ is the output associated with the proposed debt contract.

\section{A2: Efficient Stealing}

Suppose that stealing is not always wasteful, (i.e. $\lambda>1+r$ ). This occurs when the entrepreneur values the private benefits more than the cash that is necessary to generate these benefits. In this case even a self-financed monopolist would invest in private benefits.

In any case, a debt-financed entrepreneur will never produce more than $\dot{Q}$ defined as: $R^{\prime}(\dot{Q})=\lambda c$ since beyond that point the marginal revenue from production is lower than the benefit from stealing the additional funds expended in the production of the extra units. Note that because $\lambda>1+r$ and $R(Q)$ is concave we must have $\dot{Q} \leq Q^{M}$.

Define $\dot{K}$ as $R(\dot{Q})-\dot{K}(1+r)=\lambda(E+\dot{K})$.

$\dot{K}$ is the maximum principal amount of a loan that the entrepreneur can be expected to repay while producing the quantity $\dot{Q}$. However, $\dot{Q}$ can be produced with a loan $\dot{K}$ only 
if $E+\dot{K} \geq c \dot{Q}$. Recall that $\hat{Q}$ is the maximum capacity that the capital market will finance when the entrepreneur contributes an amount E. If $\hat{Q} \leq \dot{Q}$ then capital markets are not willing to finance $\dot{Q}$ and the equilibrium is similar to the constrained equilibrium described in Proposition 1 with $Q=\hat{Q}, K=c \hat{Q}-E$ and no stealing. When parameters are such that $\hat{Q}>\dot{Q}$ then $E+\dot{K}>c \dot{Q}$ and in equilibrium $Q=\dot{Q}, K=\dot{K}$ and the entrepreneur steals $(E+\dot{K}-c \dot{Q})$.

This result is essentially the same as Proposition 1, except that the unconstrained monopolist enjoys private benefits.

\section{A3: Relationship with Jensen and Meckling (1976)}

Jensen and Meckling (1976) set forth a graphical analysis of an owner-manager's choice between perquisites and value maximization. The choice is determined by a tangency between a "budget constraint" and a set of indifference curves, as illustrated in Figure 3(a). The vertical axis measures the market value of the firm $(V)$. The horizontal measures the market value of perquisites, i.e. loss of market value resulting from the consumption of managerial perquisites $(F)$. The budget line has a slope of -1 . It hits the horizontal access when the value of the firm is zero. Convex indifference curves in $(V, F)$ space represent the managers preferences between creating value and consuming perquisites. An owner-manager makes an efficient choice at a point of tangency between an indifference curve and the budget line. An increase in scale up to the monopoly level shifts out the budget line. 
We now interpret our monopoly model with a similar graphical analysis. Consider a firm with financial capital $\mathrm{E}+K$. Assume that the firm is debt-financed as described above. The market value of the firm and the market value of perquisites depend on the scale of operation chosen by the entrepreneur. Ignoring bankruptcy, the value of the firm's equity is $V=\frac{R(Q)}{1+r}-K$. The entrepreneur's consumption of managerial perquisites is $Z=\lambda(E+K-c Q)$. Combining these two conditions to eliminate Q gives $V=\frac{1}{(1+r)} R\left(\frac{E+K}{c}-\frac{Z}{\lambda c}\right)-K$

The value of the firm when perquisites are zero is $\bar{V}=\frac{1}{(1+r)} R\left(\frac{E+K}{c}\right)-K$. Therefore, continuing to ignore bankruptcy, $V=\bar{V}+\frac{1}{(1+r)}\left[R\left(\frac{E+K}{c}-\frac{Z}{\lambda c}\right)-R\left(\frac{E+K}{c}\right)\right]$. The market value of perquisites $Z$ is $F=\frac{1}{(1+r)}\left[R\left(\frac{E+K}{c}\right)-R\left(\frac{E+K}{c}-\frac{Z}{\lambda c}\right)\right] . \quad$ Therefore, we have the relationship $V=\bar{V}-F$ corresponding to the downward-sloping "budget constraint" in Jensen and Meckling's diagram.

The indifference curves for the entrepreneur are constructed as follows. Since the revenue function $\mathrm{R}(\mathrm{Q})$ is concave, $F$ is an increasing, convex function of $Z$. Inverting this relationship expresses the consumption of managerial perquisites as a increasing, concave function of their market value, $Z=\mathrm{Z}(F)$. The utility of the entrepreneur is $U=V+\frac{Z}{1+r}$, or, equivalently, $U=V+\frac{Z(F)}{1+r}$. Thus, the entrepreneur has downwardsloping, convex indifference curves in $(V, F)$ space. 
The indifference curve for utility level $U_{\mathrm{o}}$ is defined by $V=U_{\mathrm{o}}-\frac{\mathrm{Z}(F)}{1+r}$. Note that $\mathrm{Z}(0)=0$ and $\mathrm{Z}^{\prime}(0)=\frac{\lambda c(1+r)}{R^{\prime}\left(\frac{E+K}{c}\right)}$. Therefore the slope of the indifference curve at $F=0$ is $-\frac{\lambda c}{R^{\prime}\left(\frac{E+K}{c}\right)}$. Consequently, $F=0$ is optimal for the entrepreneur if and only if $R^{\prime}\left(\frac{E+K}{c}\right) \geq \lambda c$, which is to say that discounted marginal revenue exceeds the marginal value of perquisities.

Recall that $\frac{R^{\prime}\left(Q^{M}\right)}{1+r}=c$ at the neoclassical monopoly solution. Therefore, if there were no possibility of bankruptcy, there would be no agency costs of debt, and the neoclassical monopoly outcome would be feasible, (assuming $0<\lambda<1+\mathrm{r}$.) This case is illustrated in Figure 3(a).

Bankruptcy is accounted for as follows. When bankruptcy is possible the value of the firm is $V=\max \left\{\frac{R(Q)}{1+r}-K, 0\right\}=\bar{V}-\min \left\{\frac{1}{1+r}\left[R\left(\frac{E+K}{c}\right)-R\left(\frac{E+K}{c}-\frac{Z}{\lambda c}\right)\right], \bar{V}\right\}=\bar{V}-\min \{F, \bar{V}\}$

Once the market value of the firm is driven to zero, any further consumption of perquisites does not reduce the market value of the firm, because the loss is shifted to debt-holders. Therefore, the "budget constraint" in $(V, F)$ space is piecewise linear, as illustrated in Figure 3(b) and (c). It is downward-sloping with a unit slope in the positive orthant, and becomes flat once it hits the horizontal axis. 
This non-convex budget constraint allows for two local maxima of the

entrepreneur's problem: one occurs where $F=0$, and the other where $F=\frac{R\left(\frac{E+K}{c}\right)}{1+r}$. Thus, the entrepreneur either devotes all financial capital of the firm to production, or consumes it all in managerial perquisites and declares bankruptcy. The first possibility is the global maximum when $K$ is sufficiently small. The second possibility is the global maximum as $K$ approaches the neoclassical monopoly scale, under the condition of the Proposition. The solution $K=c \hat{Q}-E$ is the scale at which the two local maxima have the same value.

\section{A4: Proof of Proposition 2}

Clearly, the standard Cournot equilibrium can be supported as long as

$$
\left[P\left(n q^{n}\right)-(1+r+\lambda) c\right] q^{n} \geq-(1+r) e \quad \text { or } \quad e \geq e^{n}=\left[-\frac{\left[P\left(n q^{n}\right)-(1+r+\lambda) c\right] q^{n}}{1+r}\right]^{+}
$$

Suppose that this is case and assume that there is another equilibrium. In this equilibrium all firms can obviously not be constrained by the market, that is we cannot have $q_{i}=q_{i}^{c}\left(Q_{-i}\right)$ for all firms since the symmetric equilibrium is unique. Similarly all firms cannot be constrained by the capital market, that is $q_{i}<q_{i}^{c}\left(Q_{-i}\right)$ for all $i$ since then we would have $[P(Q)-(1+r+\lambda) c] Q=-(1+r) E$ and $[P(Q)-(1+r+\lambda) c] q_{i}=-(1+r) e$ for all $i$ which, given the inequality $\left[P\left(n q^{n}\right)-(1+r+\lambda) c\right] q^{n} \geq-(1+r) e$ would imply $q_{i}=q>q^{n}$ for all $i$. This of course cannot be an equilibrium. Therefore, we must have 
$q_{i}<q_{i}^{n}\left(Q_{-i}\right), P^{\prime} q_{i}+P>(1+r) c$ and $[P(Q)-(1+r+\lambda) c] q_{i}=-(1+r) e$ for some $i$, and

$q_{j}=q_{j}^{n}\left(Q_{-j}\right), \quad P^{\prime} q_{j}+P=(1+r) c$ and $[P(Q)-(1+r+\lambda) c] q_{j} \geq-(1+r) e$ for some $j$.

Comparing the incentive-compatibility expressions yields $q_{j} \leq q_{i}$ while comparing the

Cournot first-order conditions yields $q_{j}>q_{i}$, an obvious contradiction.

Now assume that the unique and symmetric Cournot equilibrium cannot be supported by the amount of inside equity., that is $\left[P\left(n q^{n}\right)-(1+r+\lambda) c\right] q^{n}<-(1+r) e$. A similar argument to the one above shows that we must have $q_{i}=\hat{q}^{n}$ for all $i$. .

Finally note that if the total level of inside equity cannot support the unconstrained equilibrium for $n$ entrepreneurs, it cannot do so for $(n+1)$ entrepreneurs either. To see why, if the uncontrained equilibrium cannot be supported with $n$ entrepreneurs, we have $\left[P\left(n q^{n}\right)-(1+r+\lambda) c\right] q^{n}<-(1+r) e$ and summing across firms $\left[P\left(Q^{n}\right)-(1+r+\lambda) c\right] Q^{n}<-(1+r) E$

Therefore,

$Q^{n+1} \geq Q^{n} \Rightarrow\left[P\left(Q^{n}\right)-(1+r+\lambda) c\right] Q^{n} \leq\left[P\left(Q^{n}\right)-(1+r+\lambda) c\right] Q^{n}<-(1+r) E$

which implies that the unconstrained equilibrium cannot be supported with this level of inside equity either.

\section{A5: Dynamics of Monopoly}

We analyze how a longer horizon can relax the credit market incentivecompatibility constraint that limits industry scale in a one-period market. We develop the analysis for the case of a monopoly similar to the one before, except that the market 
remains open for two periods. We demonstrate conditions under which the neoclassical monopoly output obtains in the two-period model but not the one-period model, and conversely.

Output is produced at two dates: $t \in\{1,2\}$. In each period, demand is the same as before. All inputs are variable, and must be purchased in advance of production in each period. The production technology is constant returns as before and the interest rate is constant over time.

We allow for long-term loan contracts, although these do not play a significant role in our analysis. At the beginning of period $t$, the capital market advances $K_{t}$, and, at the end of the period, the firm repays $(1+r) K_{t}$. From an outside investor's perspective a long term loan contract is equivalent to a sequence of short-term contracts.

The market unfolds as follows. At the beginning of period 1, the entrepreneur invests financial capital $E_{1}=E$, as in the one-period model. The capital market supplies additional funds $K_{1}$, and the firm produces $Q_{1}=\frac{E_{1}+K_{1}}{c}$. At the beginning of period 2, the entrepreneur has accumulated equity $E_{2}=R\left(Q_{1}\right)-(1+r) K_{1}$, and produces $Q_{2}=\frac{E_{2}+K_{2}}{c}$. The entrepreneur's payoff at the end of the second period is

\footnotetext{
${ }^{13} \mathrm{We}$ assume that entrepreneur is free to arrange credit on any terms satisfying this condition and the additional incentive compatibility conditions introduced below. A standard long-term loan contract advances funds in stages. An outside investor lends 1 dollar in period 1 and another $k=K_{2} / K_{1}$ dollars in period 2. The firm repays $(1+r)$ at the end of period 1 and another $(1+r) k$ at the end of period 2. This staged-finance contract is analogous to that analyzed by Bolton and Scharfstein (19xx), who make different assumptions about contractibility. Indeed, they consider the opposite case in which investment funds are contractible but sales revenues are not.
} 
$\pi_{2}=R\left(Q_{2}\right)-(1+r) K_{2}$. There is no payoff at the end of the first-period, because profits are fully reinvested assuming $K_{2}>0$.

Capital market incentive-compatibility constraints assure outside investors that the entrepreneur has no incentive to spend on managerial perquisites. The second-period constraint is

$$
\pi_{2} \geq \lambda c Q_{2}
$$

The first-period constraint is

$$
\frac{\pi_{2}}{1+r} \geq \lambda c Q_{1}+\frac{\bar{\pi}}{1+r}
$$

where $\bar{\pi}$ is the second-period expected profit an entrepreneur who defaults in the first period.

The value of $\bar{\pi}$ depends whether the entrepreneur's monopoly property right is

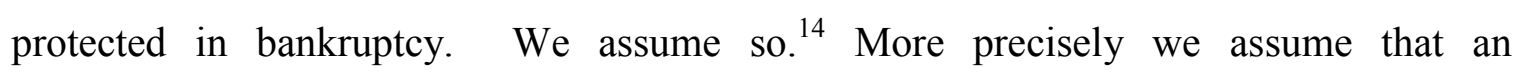
entrepreneur who defaults cannot be prevented from starting a new firm but that funds that are converted into private benefits cannot be used as equity. Let $\hat{Q}_{0}$ be the strictly positive root of $R\left(\hat{Q}_{0}\right)-(1+r+\lambda) c \hat{Q}_{0}=0$, and assume $\hat{Q}_{0}<Q_{M}$. Then an entrepreneur with zero equity at the beginning of the second-period produces $\hat{Q}_{0}$ with borrowed funds, and earns an end-of-period profit $\bar{\pi}=\lambda c \hat{Q}_{0}$. Therefore, the first-period incentive compatibility constraint is

$$
\frac{\pi_{2}}{1+r} \geq \lambda c\left(Q_{1}+\frac{\hat{Q}_{0}}{1+r}\right)
$$

\footnotetext{
${ }^{14}$ The exact solution of the dynamic game obviously depends upon the entrepreneur's outside option; however, the qualitative insights are robust.
} 
Suppose that the two incentive compatibility constraints are slack. It is straightforward to prove that optimal credit market arrangements allow the neoclassical monopoly output $Q^{M}$ in both periods. At the neoclassical solution, the entrepreneur earns

$$
\pi_{2}=(1+r)^{2} E+(2+r)\left[R\left(Q^{M}\right)-(1+r) c Q^{M}\right]
$$

All of the entrepreneur's return comes at the end of the second period, and consists of a normal return on inside equity plus compounded monopoly rents. At the neoclassical solution, the first-period incentive constraint implies the second-period constraint. Therefore, both constraints are indeed satisfied if

$$
E \geq \frac{\lambda c}{1+r}\left(Q^{M}+\frac{\hat{Q}_{0}}{1+r}\right)-\frac{2+r}{(1+r)^{2}}\left[P\left(Q^{M}\right)-(1+r) c\right] Q^{M}
$$

How does this industry outcome contrast with the one period model? In the one period model, an entrepreneur with equity $E$ is constrained by the credit market if $\hat{Q}<Q^{M}$. This condition is equivalent to

$$
E<-\frac{\left[P\left(Q^{M}\right)-(1+r+\lambda) c\right] Q^{M}}{1+r}
$$

Therefore, we have the following result.

Proposition 4 If

$$
\frac{\lambda c}{1+r}\left(Q^{M}+\frac{\hat{Q}_{0}}{1+r}\right)-\frac{2+r}{(1+r)^{2}}\left[P\left(Q^{M}\right)-(1+r) c\right] Q^{M} \leq E<-\frac{\left[P\left(Q^{M}\right)-(1+r+\lambda) c\right] Q^{M}}{1+r}
$$

then $Q_{1}=Q_{2}=Q^{M}$ in the two-period model, while $Q<Q^{M}$ in the oneperiod model . 
Thus there exist a range of circumstances when the capital market constrains industry scale in the one-period monopoly model, but not in the two-period model. The conditions defining these circumstances are nondegenerate if

$$
\frac{\lambda c}{1+r}\left(Q^{M}+\frac{\hat{Q}_{0}}{1+r}\right)-\frac{2+r}{(1+r)^{2}}\left[P\left(Q^{M}\right)-(1+r) c\right] Q^{M}<-\frac{\left[P\left(Q^{M}\right)-(1+r+\lambda) c\right] Q^{M}}{1+r} .
$$

A few simple algebraic manipulations reduce this inequality to

$$
R\left(Q^{M}\right)-(1+r) c Q^{M}>\lambda c \hat{Q}_{0},
$$

which must hold given the definition of $\hat{Q}_{0}$ and $Q^{M}$ (i.e. the very definition of these variables yields $\left.R\left(Q^{M}\right)-(1+r) c Q^{M}>R\left(\hat{Q}_{0}\right)-(1+r) c \hat{Q}_{0}=\lambda c \hat{Q}_{0}\right)$.

\section{A6: Proof of Proposition 3}

Define $\hat{q}\left(Q, e_{i}\right) \quad$ and $\quad \bar{q}(Q) \quad$ respectively by the equations $[P(Q)-(1+r+\lambda) c] \hat{q}\left(Q, e_{i}\right)=-(1+r) e_{i}$ and $P^{\prime}(Q) \bar{q}(Q)+P(Q)=(1+r) c$. If $\mathrm{Q}$ is the total equilibrium output, then each firm's output is described by $q_{i}(Q)=\min \left\{\hat{q}\left(Q, e_{i}\right), \bar{q}(Q)\right\}$. It is easy to verify that both $\hat{q}\left(Q, e_{i}\right)$ and $\bar{q}(Q)$ are decreasing functions of $Q$. As a consequence $q_{i}(Q)$ is also decreasing in $Q$ and the fixed point $Q=\sum_{i} q_{i}(Q)$ is unique which implies that any equilibrium is also unique.

Suppose that firm $i$ is constrained then $[P(Q)-(1+r+\lambda) c] q_{i}=-(1+r) e_{i}$ and $q_{i}<q_{i}^{n}\left(Q_{-i}\right)$. The last inequality implies $P^{\prime}(Q) q_{i}+P(Q)>(1+r) c$. If firm $j$ is not 
constrained then $[P(Q)-(1+r+\lambda) c] q_{j} \geq-(1+r) e_{j}$ and $q_{j}=q_{j}^{n}\left(Q_{-j}\right)$ which implies $P^{\prime}(Q) q_{j}+P(Q)=(1+r) c$. Given the model's assumptions, and the fact that in equilibrium all funds are used for production:

a) the first order conditions above clearly imply $q_{i}<q_{j}$ and $e_{i}+k_{i}<e_{j}+k_{j}$;

b) the two incentive compatibility constraints imply

$$
-\frac{(P-(1+r+\lambda) c)}{(1+r) c}=\frac{e_{i}}{e_{i}+k_{i}} \quad-\frac{(P-(1+r+\lambda) c)}{(1+r) c} \leq \frac{e_{j}}{e_{j}+k_{j}}
$$

which clearly implies $\frac{e_{i}}{e_{i}+k_{i}} \leq \frac{e_{j}}{e_{j}+k_{j}}$. This inequality implies that if $e_{i}>e_{j}$ then $k_{i}>k_{j}$.

Since we have $e_{i}+k_{i}<e_{j}+k_{j}$ we can therefore not have $e_{i}>e_{j}$. Therefore unconstrained firms have more equity than constrained firms.

If firms $\mathrm{i}$ and $\mathrm{j}$ are both constrained it is straightforward that $\frac{e_{i}}{e_{i}+k_{i}}=\frac{e_{j}}{e_{j}+k_{j}}$ and that $e_{i}<e_{j} \Rightarrow k_{i}<k_{j} \Rightarrow q_{i}<q_{j}$. Finally it is obvious that when a constrained firm $i$ is split into $m$ smaller firms $e_{i}=\sum_{j=1}^{m} e_{i j}$, in the new equilibrium the output of the original firm is simply split among the new firms proportionally to equity $q_{i j}=\frac{e_{i j}}{e_{i}} q_{i}$ since $[P(Q)-(1+r+\lambda) c] q_{i j}=-(1+r) e_{i j}$ and $P^{\prime}(Q) q_{i j}+P(Q)>(1+r) c$ 


\section{REFERENCES}

Albuquerque, Rui and Hugo A. Hopenhayn, 2002, "Optimal Lending Contracts and Firm Dynamics," Review of Economic Studies, forthcoming.

Allen, Franklin and Douglas Gale, 2000, "Corporate governance and competition", Corporate governance: theoretical and empirical perspectives, Xavier Vives ed., Cambridge University Press, 23-84.

Amir, Rabah, and Val E. Lambson, 2000,"On the effects of entry in Cournot markets", Review of Economic Studies, 67, 235-254.

Brander, James and Tracy Lewis, 1986, "Oligopoly and Financial Structure: The Limited Liability Effect", American Economic Review, 76, 956-970.

Bolton, Patrick and David Scharfstein, 1990, “A Theory of Predation Based on Agency Problems in Financial Contracting", American Economic Review, 80, 93-106.

Brander, James and Tracy Lewis, 1986, "Oligopoly and Financial Structure: The Limited Liability Effect", American Economic Review, 76, 956-970.

Busse, Meghan R., 2002, "Firm Financial Condition and Airline Price Wars," RAND Journal of Economics, 33, 298-318.

Chevalier, Judith A., 1995a, "Capital Structure and Product-Market Competition: Empirical Evidence from the Supermarket Industry," American Economic Review, 85, 415-35.

Chevalier, Judith A. 1995b, "Do LBO Supermarkets Charge More? An Empirical Analysis of the Effects of LBOs on Supermarket Pricing," Journal of Finance, 50, 1095112.

Chevalier, Judith A. and David S. Scharfstein, 1995, "Liquidity Constraints and the Cyclical Behavior of Markups", American Economic Review, 85(2), 390-96.

Chevalier, Judith A. and David S. Scharfstein, 1996, "Capital-Market Imperfections and Countercyclical Markups: Theory and Evidence", American Economic Review, 86(4), 703-25.

Hart, Oliver D., 1983, "The market mechanism as an incentive device", The Bell Journal of Economics, 14, 366-382.

Hermalin, Benjamin E., 1992, "The effect of competition on executive behavior", RAND Journal of Economics, 23(3), 350-365. 
Jensen, Michael C., and William H. Meckling, 1976, "Theory of the Firm: Managerial Behavior, Agency Costs and Ownership Structure", Journal of Financial Economics, 3(4), 305-60.

Kovenock, Dan and Gordon M. Phillips, 1997, "Capital Structure and Product Market Behavior: An Examination of Plant Exit and Investment Decisions", Review of Financial Studies, 10(3), 767-803.

Kreps, David M. and Jose A. Scheinkman, 1983, "Quantity Precommitment and Bertrand Competition Yield Cournot Outcomes”, Bell Journal of Economics, 14(2), 326-37.

Maksimovic, Vojislav, 1988, "Capital Structure in Repeated Oligopolies", RAND Journal of Economics, 19, 389-407.

Modigliani, Franco and Merton Miller, 1958, "The Cost of Capital, Corporate Finance, and the Theory of Investment", American Economic Review, 48, 261-97

Phillips, Gordon M., 1995, "Increased Debt and Industry Product Markets: An Empirical Analysis", Journal of Financial Economics, 37(2), 189-238.

Raith, Michael, 2002, "Competition, Risk and Managerial Incentives", forthcoming in American Economic Review.

Salant, Stephen, Sheldon Switzer, and Robert J. Reynolds, 1983, "Losses from horizontal merger: the effects of an exogenous change in industry structure on Cournot-Nash equilibrium", Quarterly Journal of Economics, 98(2), 185-199.

Scharfstein, David, 1988, "Product-market competition and managerial slack", $R A N D$ Journal of Economics, 19(1), 147-155.

Schmidt, Klaus M., 1997, "Managerial incentives and product market competition", Review of Economic Studies, 64, 191-213.

Showalter, Dean M., 1995, “Oligopoly and Financial Structure: Comment”, American Economic Review, 85, 647-653.

Showalter, Dean M., 1999, "Debt as an Entry Deterrent under Bertrand Price Competition", Canadian Journal of Economics, 32, 1069-81.

Townsend, Robert M, 1979,"Optimal contracts and competitive markets with costly state verification", Journal of Economic Theory, 21(2), 265-293.

Williams, Joseph T, 1995, "Financial and Industrial Structure with Agency", Review of Financial Studies, 8(2), 431-74. 


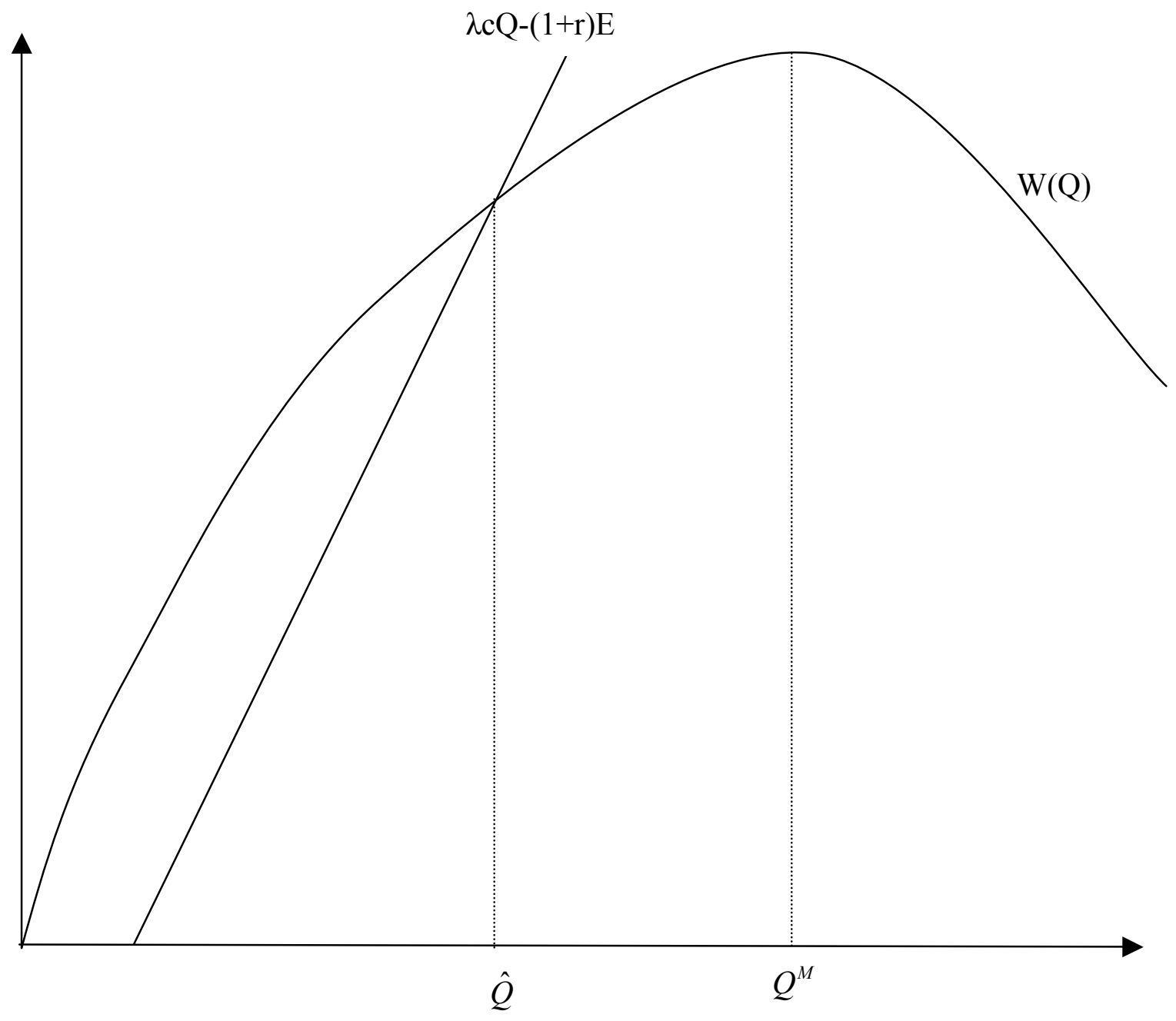

Figure 1:

Output is constrained below the monopoly level. 


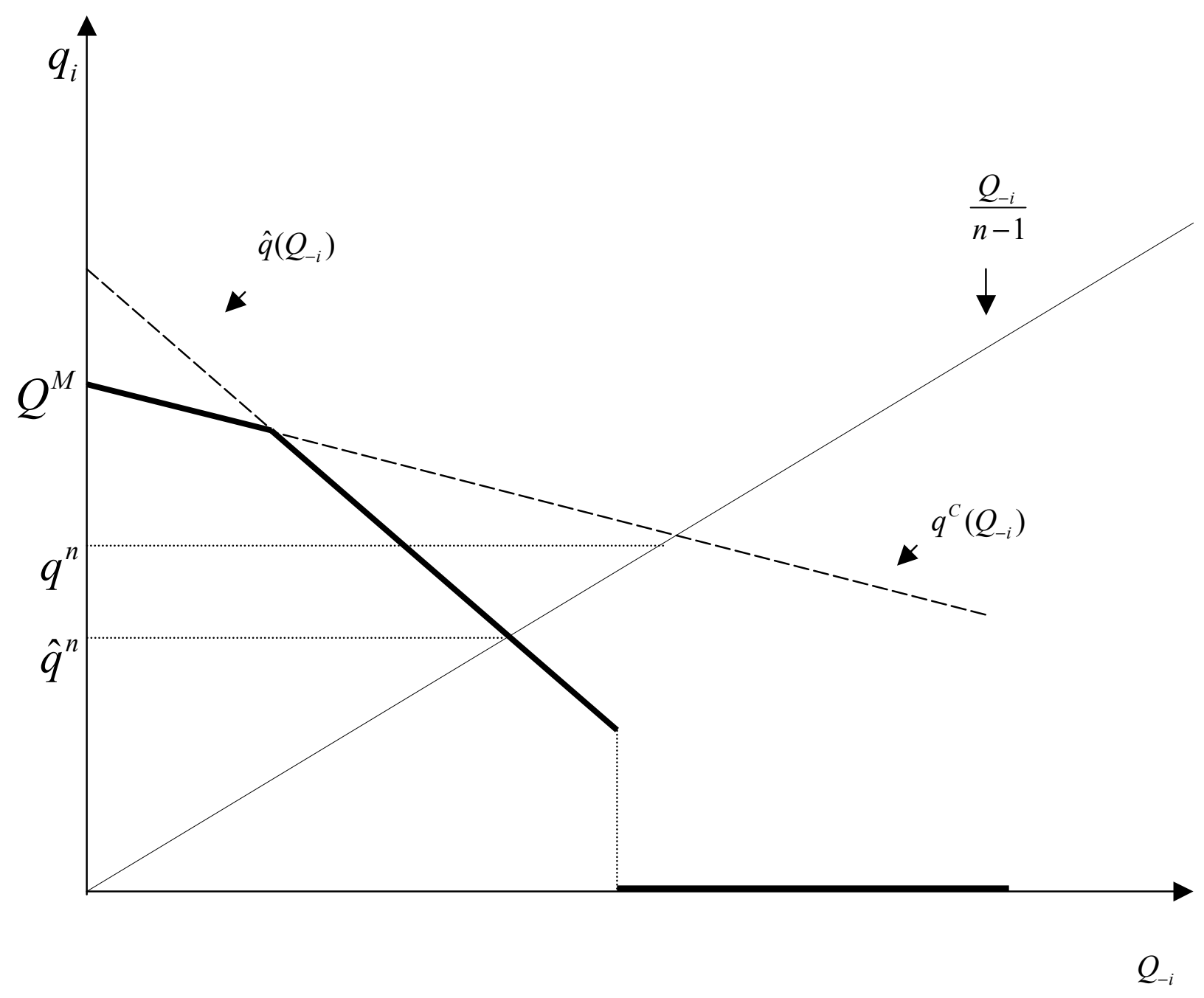

Figure 2:

Capital market constrains best response curve. 


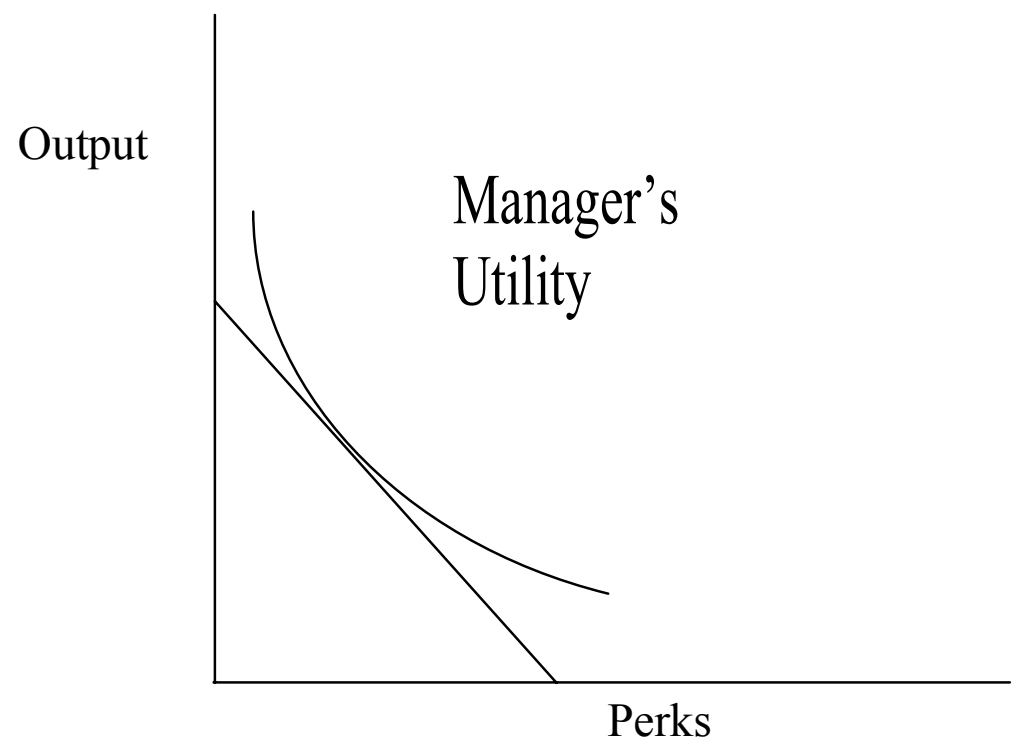

(a)

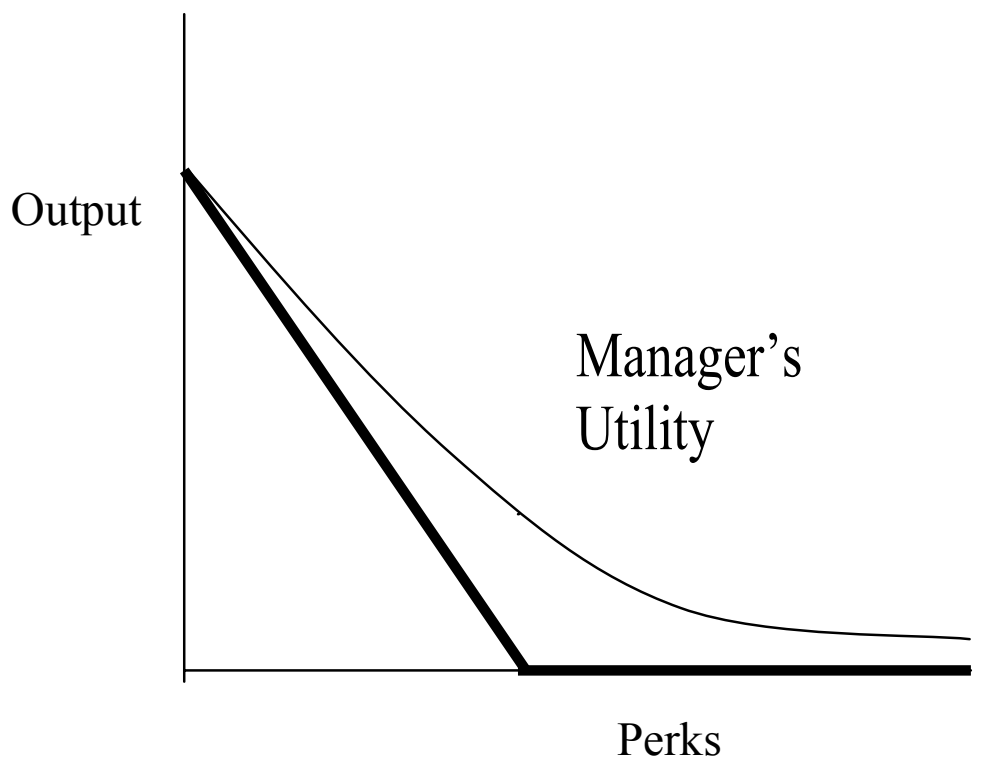

(b)

Figure 3:

The entrepreneur's choice between production and perquisites:

(a) Jensen and Meckling (1976)

(b) The unconstrained entrepreneur 


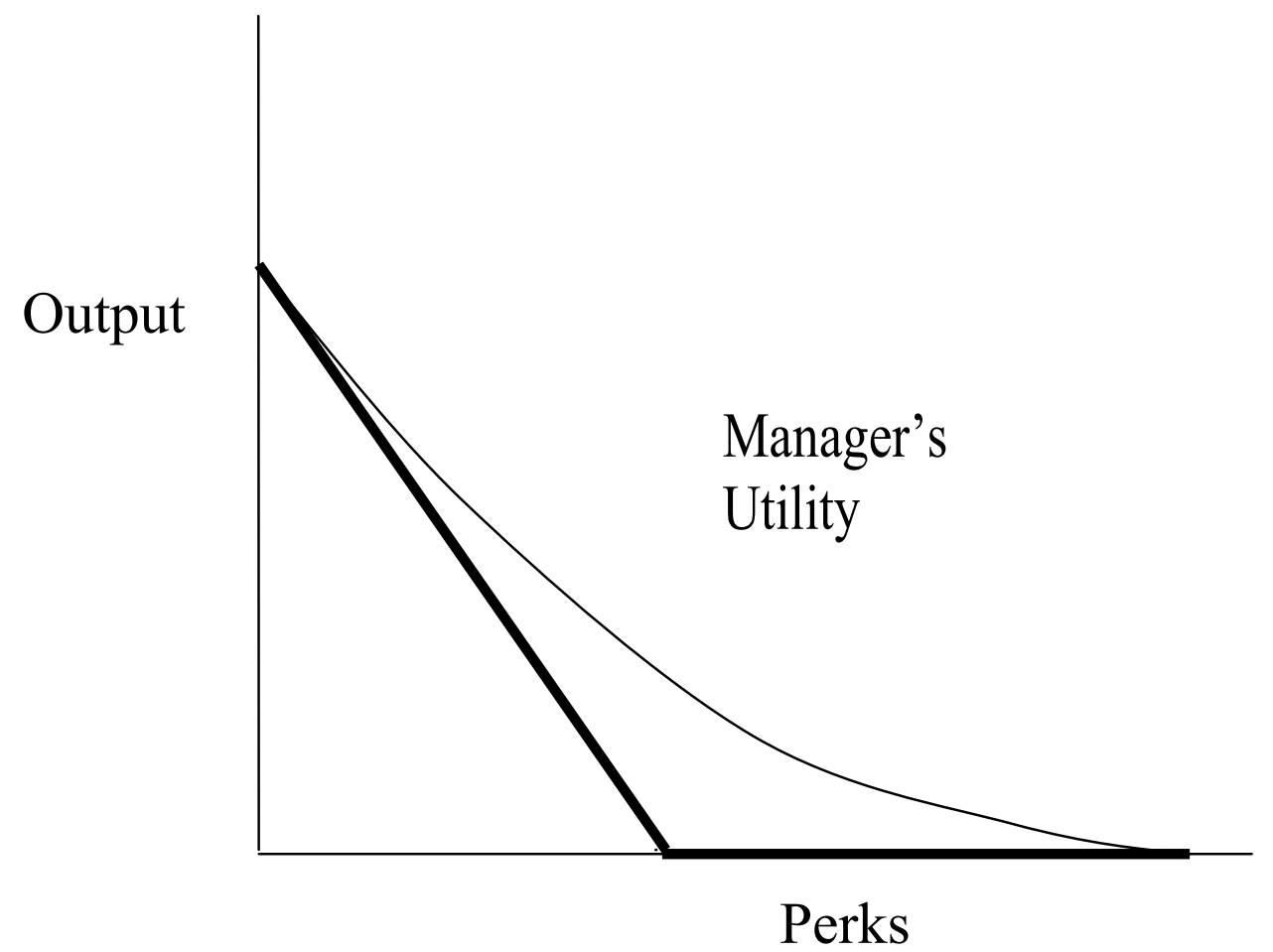

Figure 3 (c)

The entrepreneur's choice between production and perquisites: The constrained entrepreneur 